

\title{
A Cidade dos Invisíveis: a Transfobia como um Instrumento de Segregação Social e Urbana
}

\author{
La Ciudad de los Invisibles: la Transfobia como un Instrumento de \\ Segregación Social y Urbana
}

\author{
The Invisible's City: Transphobia as an Instrument of Social and Urban \\ Segregation
}

\section{Resumo}

Este artigo surgiu a partir de inquietações a respeito do que Henry Lefebvre em 1968 chamou de Direito à cidade, que seria o direto que o cidadão (no sentido de habitante da cidade) possui de não ser excluído da sociedade urbana. Segundo o autor o trabalhador tem o direito de usufruir das qualidades e benefícios que a vida urbana proporciona. As principais inquietações foram: quais cidadãos o autor falava? Quais seriam os benefícios da vida urbana aos quais ele se referia? Talvez o direito de usufruir de um passeio público, de uma praça, de uma estrutura de mobilidade urbana, de equipamentos de saúde e etc. E durante esse segundo momento surgiu a grande problematização que de fato mobilizou o projeto: Pessoas Trans possuem direito à cidade? Compreende-se por pessoas trans o conjunto heterogêneo formado por travestis, por homens e mulheres transexuais. Ou seja, pessoas que vivenciam o gênero de maneira diversa ao que foi de socialmente imposto ao nascimento. A estas pessoas são atribuídas uma série de estigmas que produzem um complexo cenário de exclusão social e marginalização, que perpassa pelas ruas da cidade interferindo diretamente no modo dessas pessoas perceberem e de viverem a cidade.

Palavras-Chave: Transfobia; Transgêneros; Sociabilidade; Urbanismo; Direito À Cidade.

\section{Resumen}

Este artículo surgió de los cuestionamientos respecto de lo que Henry Lefebvre en 1968 llamo de "derecho a la ciudad". Según el autor el trabajador tiene derecho a usufructuar de las cualidades y beneficios que la vida urbana proporciona. A pesar de ser válido, tal cuestionamiento excluye a las personas trans en lo respecta al derecho a la ciudad. Se comprende por personas trans, al conjunto heterogéneo formado por travestis, por hombres y mujeres transexuales. $\mathrm{O}$ sea, personas que viven el género de maneras diversas a lo que fue socialmente impuesto al momento de nascer. A estas personas se le son atribuidos una seria de estigmas que producen un complejo escenario de exclusión social y marginalización, que permea por las calles de la ciudad interfiriendo directamente en el modo como estas personas vivencian la ciudad.

Palabras-Clave: Transfobia; Transgéneros; Sociabilidad; Urbanismo; Derecho A La Ciudad.

\section{Abstract}

This article came from the concerns about what Henry Lefebvre in 1968 called the 'right to the city'. According to the author, the worker has the right to enjoy the qualities and benefits that urban life provides. Although valid, such questioning excludes trans people with regard to the right to the city. I understand by trans people the heterogeneous set formed by transvestites, by transsexual men and women. That is, people who experience the gender differently from what was socially imposed at birth. These people are attributed a series of stigmas that produce a complex scenario of social exclusion and marginalization, which runs through the streets of the city directly interfering with the way these people experience the city.

Keywords: Transphobia; Transgender; Sociability; Urbanism; Right To The City. 
A Geografia compreende a cidade como o aglomerado de pessoas e edificações em torno de um espaço geográfico circunscrito. Para Argan (1999 apud GUEDES, 2003) a cidade é uma entidade social e política organizada a partir da arquitetura e das técnicas construtivas. A cidade para Durkheim (1999 apud ICASURIAGA; RAMOS, 2012) é um espaço no qual se aglomeram pessoas, meios de produção, comunicação e transportes. Já para Lynch (2006), a cidade não é feita somente da sua estrutura física ou de suas formas arquitetônicas, as cidades são constituídas de elementos móveis e dinâmicos, como as pessoas, suas atividades e suas interações. A cidade, para este autor é então o conjunto dos construtos arquitetônicos e da vida que a circunda.

$\mathrm{Na}$ fenomenologia os sentidos que se apresentam a partir de um signo podem variar de acordo com os aspectos subjetivos do seu observador, suas vivências, suas experiências, suas visões de mundo e de seus instrumentos de análise. Deste modo, ao analisarmos a cidade enquanto fenômeno, podemos perceber que, embora a essência do fenômeno seja única, outros sentidos podem ser apreendidos a partir da percepção dos sujeitos, que varia de acordo com a sua interação, com a sensação de pertencimento à comunidade e pelas relações com que os habitantes mantém com estas cidades. São vários os fatores que constroem a nossa visão de cidade, como demonstra Schweickardt (2000) no trecho a seguir:

A forma de vermos a cidade vai depender da posição que ocupamos dentro dela. Se estivermos de um lado da rua teremos uma visão diferente se tivermos do outro lado, assim como olhamos a cidade com olhos de quem não nasceu aqui, que não se criou neste lugar, nem é desta cultura. Ao olhar a cidade, olhamos sob um determinado ponto de vista, com uma determinada forma e uma determinada bagagem teórica e metodológica. Por isso queremos dizer que o nosso olhar partirá do pressuposto fenomenológico porque acreditamos que ele nos dá pistas para entender que a cidade não é somente ruas, prédios, pessoas e coisas simplesmente; mas está tecida por uma infinita rede de inter-relações, de significações e de intencionalidades que formamos "espírito" da cidade. (p. 129)

Aceitando-se que a visão sobre a cidade é subjetiva e que varia de acordo com a percepção de quem a observa, este trabalho se propõe a analisar a cidade sob a ótica daqueles que apesar de integrarem a urbe, são diuturnamente excluídos do convívio em sociedade: os transexuais, transgêneros e travestis, doravante denominadas pessoas trans. Carvalho e Macedo Jr (2017), reforçam o sentido desta exclusão ao afirmar que:

A cidade se ergue como um reflexo e como proteção das ideias e valores dominantes. A sociedade, que compõe a cidade, é heteronormativa, isto é, assimila a heterossexualidade como norma sexual legítima e moralmente constituída. Assim, a cidade também se constitui enquanto um ambiente que mitiga subjetividades, rejeitando as sexualidades e identidades de gênero desviantes da norma sexual 
Ao se analisar a cidade e as relações humanas que ocorrem nela, podemos perceber que a vida citadina é orientada pelas variáveis espaço e tempo. $\mathrm{O}$ espaço refere-se às zonas ocupadas, às distâncias percorridas e as relações sócio espaciais e o tempo refere-se tanto ao tempo cronológico, medido em horas,dias, meses e etc., quanto existencial que é segundo Heidegger (1989 apud BATISTA, 2006) o tempo de vida (existencial) expressa a essência do homem como ser-no-mundo.

Para Husserl (2004 apud BARCO, 2012), o espaço não se define matematicamente, ele se exibe intuitivamente e, portanto, deve ser investigado sob a ótica da filosofia. Para ele o espaço pode ser compreendido através de três dimensões: uma intuitivo-psicológica, que se refere ao modo como os sujeitos o percebem. Essa dimensão pode ser fruto da intuição ou de um processo reflexivo; a dimensão lógico-geométrica que representa a uma preocupação com a representação geométrica e com os seus propósitos cognitivos (medir, calcular, construir e etc.), abstraindo-se a percepção e as experiências sensoriais dos sujeitos em prol de um conceito intersubjetivo que relaciona a ideia de racionalização da realidade; e a última dimensão descrita por Husserl é a metafísica, que trata do espaço em si, independentemente de qualquer experiência humana ou representação geométrica. A dimensão metafísica representa a realidade e a existência substancial do espaço, seria uma dimensão resultante das dimensões anteriores (HUSSERL, 2004 apud BARCO, 2012).

O tempo na cidade (capitalista) moderna é orientado a partir de uma lógica produtiva. Organizamos o dia de maneira a suprir tanto as necessidades da vida humana quanto as necessidades da produção capitalista: acordamos pela manhã, nos alimentamos, realizamos nossas atividades laborais e ao anoitecer, nós retornamos às nossas residências e dormimos, nos preparando para a próxima jornada. Desse modo, ao se analisar a vida na cidade, através das variáveis tempo e espaço, podemos perceber que o tempo se relaciona intimamente com o espaço de modo que o uso do espaço urbano e, portanto, o uso da cidade é planejado para a manutenção desta dinâmica produtiva e da decorrente ordem social que se origina dela.

Uma das possíveis interpretações para o fenômeno da cidade nasce a partir das reinterpretações dos modelos biológicos de cidade, que a compreendem a partir da metáfora de um organismo vivo ${ }^{1}$, que se encontra em constante crescimento, movimento e evolução. Nessa metáfora, considera-se que cada setor da cidade e cada indivíduo desempenham uma função vital e indispensável ao seu equilíbrio e funcionamento. Park (1967) propõem uma ampliação deste conceito compreendendo que além de viva, a cidade se encontra imersa em um sistema ecológico ${ }^{2}$, no qual os diversos organismos que a habitam interagem entre si através de relações ecológicas, como

1 A metáfora da cidade como organismo vivo remontam um modelo bastante utilizado durante a Idade Média para referir-se às zonas da cidade e os atores sociais que nela interagiam como partes do corpo, relacionando-os a uma função orgânica. Entretanto, a Escola sociológica de Chicago apresenta um aperfeiçoamento desta leitura com a utilização de terminologias específicas das ciências naturais tais como tecido, artérias, coração, função e etc. para explicar os processos de crescimento urbano.(BARROS,2011) 
Portanto, podemos dizer que tal como em um sistema biológico ou bioma, a cidade 'acorda' com a luz do sol: inicia-se o fluxo de pessoas e veículos, os estabelecimentos (comerciais, educacionais, religiosos e de serviços) entram em funcionamento e logo, a vida na cidade se dinamiza e se intensifica ao decorrer das horas do dia. Durante a noite, observa-se um fenômeno contrário: as ruas se tornam mais vazias, o fluxo de pessoas e veículos se torna menos intenso, a maioria dos estabelecimentos se fecham, as pessoas se recolhem ao ambiente doméstico e a cidade 'dorme'. Cada uma destas atividades desenvolvidas na cidade, e que, caracterizam a vida urbana é parte integrante deste sistema e as interações (sociais, urbanas etc.) ocorridas nestes sistemas é que movimentam e dão vida à cidade (BARROS, 2011). Desse modo podemos concluir que a cidade é ao mesmo tempo o pano de fundo destas atividades e o agente dinamizador e transformador do espaço.

Para Silva e Santos (2015) a cidade, desde as suas primeira constituições históricas, se organizou no espaço-tempo através da exploração do trabalho e da produção de desigualdades, onde a maioria da população se encontra sob as mais variadas privações, de violações de direitos sendo vítima de uma infinidade de modalidades de violência urbana ${ }^{3}$. Revelando-se assim como um espaço de exclusão, onde as minorias, sobretudo LGBT's possuem acesso reduzido aos espaços de decisão política, aos equipamento públicos ${ }^{4} \mathrm{e}$ ao desenvolvimento de políticas sociais.

Carvalho e Macedo Jr (2017), afirmam que a cidade é moldada para atender aos interesses das classes dominantes e vai se ajustando continuamente de modo a se tornar um espelho destas classes, reproduzindo não somente os seus valores e normas sociais como as suas relações de poder e dominação. Sendo a classe dominante patriarcal e heteronormativa, a cidade irá refletir estes valores, tornando-se um ambiente hostil aos que de alguma forma apresentem um comportamento sexual não normativo ou de alguma forma desviante.

\section{A Percepção da Transfobia: Corpos Trans, Corpos Indesejáveis}

Jesus (2012), afirma que embora não exista um consenso sobre o termo, transgênero diz respeito a um conceito guarda-chuva que abrange o grupo diversificado de pessoas que não se identificam com os comportamentos e/ou papéis esperados do gênero que lhes foi determinado socialmente ao nascimento. Vergueiro (2014) e Jesus (2012) afirmam que estas vivências de gênero são consideradas diferentes, incomuns e não tradicionais essa

2 Segundo alguns teóricos da Escola de Chicago, as cidades fazem parte de Sistema Ecológico que assim como na natureza. Os organismos e microrganismos vivos presentes neste sistema interagem cooperativamente para que todo o sistema (ou bioma) funcione corretamente.

3 Violência Urbana se refere ao fenômeno social resultante da situação de desigualdade e marginalidade que se encontram alguns segmentos da sociedade, conduzindo estes grupos a comportamentos desviantes. Este fenômeno é diretamente influenciado por algumas características dos próprios meios urbanos, como dimensão, densidade e heterogeneidade populacional e etc. (Esteves,1999).

4 Equipamentos públicos, refere-se a todo e qualquer equipamento de infraestrutura urbana que seja de acesso público: hospitais, escolas, igrejas e etc.

Davi Miranda 
população está suscetível a potenciais abusos, perseguições, discriminações e violência. A essa violência damos o nome de transfobia, que é toda forma de discriminação, preconceito e subalternização de pessoas trans em virtude de suas identidades de gênero.

A transfobia pode-se manifestar de variadas forma, desde a exclusão social, da negativa ao tratamento pelo nome social ${ }^{5}$, da negativa de direitos básicos (ir e vir, saúde, educação e etc), da violência verbal, física, sexual e em última instância,no extermínio. Segundo HERDT (1996, apud JESUS, 2013) esse preconceito se materializa devido à crença na anormalidade desta população, decorrente do seu não enquadramento ao gênero "natural", que é atribuído ao nascimento e a partir do qual são esperados determinados comportamentos 'adequados' a um gênero ou outro.

Ao longo da história do Brasil, em especial durante a ditadura militar, pessoas trans (mais representadas pela categoria travesti ${ }^{6}$ ) e homossexuais sofriam bastantes perseguições, embora o mote da repressão estivesse sobre os comunistas, foi observada uma forte censura a estes corpos e às suas práticas, que representavam ao Estado um risco à moral e aos costumes (PASSAMANI, 2010). As grandes mídias tiveram um papel determinante na legitimação da ação higienista do estado, uma vez que se consolidou como a criadora e disseminadora do estigma da travesti, sempre associando a imagem destas mulheres à marginalidade, drogadição, doenças sexualmente transmissíveis e principalmente como destruidoras dos valores morais e da família. Dessa forma, se inventou o estigma da Travesti.

[...] A grande imprensa de Fortaleza, mas também de outras cidades do Brasil, lançaram seu olhar, sobretudo, para a prática da prostituição travesti, produzindo um sujeito travesti marginal que assume visibilidade através de notícias relacionadas à "desordem" da cidade: brigas, assassinatos, roubos, etc. À segunda, contestamos que as roupas do estigma não foram vestidas de modo passivo pelos sujeitos (VERAS; GUASCH, 2015, p. 41).

Seja de forma velada com a censura de espetáculos de travestis e transformistas, com a publicação de textos jornalísticos que expunham 'os perigos das travestis' ou de forma mais direta com a perseguição e detenção. Durante as décadas de ditadura houve uma grande repressão e marginalização deste grupo de pessoas refletindo diretamente sobre a sociabilidade e no comportamento deste grupo, que passou a sair das ruas e a e recolher em ambiente domestico (VERAS \& GUASCH, 2015).

Os reflexos dessa estigmatização podem ser percebidos ao se analisar os dados sobre a transfobia no Brasil. A ONG brasileira Rede Trans realizou no ano de 2016 uma pesquisa com uma o assassinatos e crimes cometidos contra a população trans brasileira. Através destes dados, foram levantados que de $1^{\circ}$ de

5 Nome social é o prenome pelo qual a pessoa trans se reconhece e prefere ser chamada.

6 Até o início dos anos 80,embora se tenha registro da existência de pessoas trans o termo não era utilizado, sendo comum referirem-se a estas pessoas como travestis. A identidade transmasculina, no entanto, passou a ser discutida apenas por volta dos anos 2000 quando a categoria passou a ter organização política. 
Janeiro a 31 de Dezembro de 2017, foram cometidos contra a população trans 179 homicídios, dados da mesma ONG afirmam que no ano de 2016 foram cometidos 144 assassinatos, 52 tentativas de homicídio, 54 violações de direitos humanos e ainda, foram apurados 9 casos de suicídios motivados por transfobia (REDE TRANS, 2018) ${ }^{7}$.

Analisando os dados a respeito destes crimes percebe-se que estes caracterizam-se como crimes de ódio. Segundo Jesus (2013) estes crimes são caracterizados tanto pela forma hedionda com que são executados quanto pela prática genocida, devido à intencionalidade de que se extermine total ou parcialmente a população transgênera. A autora reitera também a conivência do estado para a perpetuação e legitimação deste extermínio, seja através da omissão, da ineficácia de políticas de segurança pública, da ausência de políticas de prevenção à violência praticada contra este grupo em específico ou através de práticas institucionais que inviabilizam a cidadania destas pessoas.

Outros dados importantes sobre estes crimes, dizem respeito ao local onde foram cometidos e o principal alvo destes ataques. O relatório de $2017 \mathrm{da}$ Articulação Nacional de Travestis e Transexuais (ANTRA, 2017) aponta que $55 \%$ dos assassinatos de pessoas trans ocorreu em via pública e que $70 \%$ destas vitimas exerciam a atividade de profissional do sexo. Estes dados produzem um discurso implícito, não verbal e simbólico, cujo sentido é disseminar entre a população trans a mensagem de que seus corpos são imorais e que a sua presença não é tolerada em espaços públicos.

A violência transfobica, não se trata apenas da pratica genocida ou da violência física, mas de todo um sistema de marginalização e exclusão social que tem atravessamentos nos demais aspectos das suas vidas. ANTRA (2017) estima que $90 \%$ das mulheres trans estejam em situação de prostituição ${ }^{8}$ devido, sobretudo, a práticas discriminatórias no âmbito do mercado de trabalho. No âmbito da educação, segundo o Observatório Trans de Educação ${ }^{9}$ os índices de evasão escolar entre as pessoas Trans gira em torno de $73 \%$ e é principalmente motivada por práticas discriminatórias, violência, pelo não reconhecimento da identidade de gênero e do nome social nas instituições de Ensino. O projeto estima que entre $3 \%$ e $5 \%$ da população trans brasileira permanece na escola até o ensino médio. E que somente $5 \%$ da população trans nacional consegue acessar uma instituição de Ensino Superior.

Embora os dados apresentados sejam preocupantes sinalizações a respeito das privações de direitos sofridas por esta população, as informações levantadas não são consideradas pelo Estado Brasileiro como dados oficiais,

7 Rede Trans(Rede Nacional de Travestis e transexuais) é a ONG responsável pela coleta e catalogação de dados qualitativos e quantitativos a respeito de homicídios e violações de direitos cometidos contra a população trans. Dados disponíveis em: www.redetransbrasil.org.br.

8 Em entrevista ao jornal El pais a travesti Keila Simpson vice-presidente da ANTRA afirma que $90 \%$ das mulheres trans e travestis trabalham na prostituição, entretanto não divulgou a fonte dos dados e nem o modo com que forma obtidos. Disponível em: https://bit.ly/2B275Kn.

9 Observatório trans de educação é um projeto criado para o Prêmio Jovem Jornalista do instituto Vladmir Herzog, a partir do qual foi criado um observatório da educação da população trans. Disponível em: www.educaçãotrans.com.br. 
visto que eles têm sido levantadas por ONG's e associações de Transexuais e Travestis e não por órgãos governamentais. $\mathrm{O}$ observatório afirma também que cerca de 93\% dos brasileiros acreditam haver preconceito contra travestis, e apenas $29 \%$ admitem ser preconceituosos e que entre $22 \%$ e $24 \%$ dos brasileiros diz não gostar de ter qualquer forma de contato com a população trans.

Estes dados demonstram que locais públicos; como instituições de ensino, lojas, locais de trabalho, ruas e avenidas e etc.; onde se supõe a garantia igualitária de acesso a todos os cidadãos, a presença de pessoas trans e travestis é considerada indesejada e nociva. Sendo comum que a população se refira a pessoas trans como perigosas, agressivas, doentes e marginais, que devem ser retiradas do convívio da sociedade, para que não a 'contamine'. Até mesmo a existência de pessoas trans é um incômodo para a sociedade cisnormativa. O simples fato de caminhar à luz do dia ou frequentar um local público, fazer compras em um supermercado movimentado ou qualquer outro hábito da vida cotidiana já representa para os habitantes do mundo dos invisibilizados, um exercício de resiliência. Como podemos perceber no trecho:

Eu me recordo, de maneira viva, o cansaço e esgotamento que sentia logo no início da transição, quando minha androginia se fazia esquisita para as pessoas cisgêneras - ao sair para o mundo externo para realizar meus estudos e trabalho, e acabar colhendo pelo caminho alguns olhares de susto, de repulsa, de vergonha e até de riso. Sim, com o tempo, eu consegui decifrar cada um deles. Eu tinha a sensação de que minha caminhada não era nunca inocente e fortuita, e que meu corpo não permitia que os olhares de transeuntes se dissipassem e se perdessem pelo espaço, mas, pelo contrário, ele parecia uma marca que direcionava e organizava pupilas alheias. (ARARUNA, 2017, p. 147)

Bachmann e Gooch (2018) produziram um relatório sobre a qualidade de vida de pessoas trans na Grã-Bretanha, expondo o impacto que a discriminação, exclusão e violência possui na vida destas pessoas. O relatório é composto pelo depoimento de mais de 800 pessoas trans binárias ou não binárias ${ }^{10}$ e demonstra que duas em cada cinco entrevistados foi vítima de um crime de ódio ou discriminação nas ruas, hospitais, locais de trabalho ou em universidades. Como se pode perceber com os seguintes relatos:

$\mathrm{Eu}$ sou um homem trans e por mais de dois anos tenho sido perseguido por uma pessoa desconhecida. Durante este tempo, tenho recebido ameaças em cartas ameaçadoras. Em duas delas continham lâminas de barbear e em outra uma substância tóxica que queimou as minhas mãos, rosto e olhos. Além disso, fui espancado três vezes. James, 47 anos. (BACHMANN; GOOCH, 2018, p. 8)

Fui agredida fisicamente por duas mulheres quando eu tentei usar o

10 Pessoas trans não binárias são pessoas que se reconhecem parcialmente comum gênero e parcialmente com outro ou ainda com nenhum deles. 
banheiro em um bar. Elas começaram a me empurrar, gritando que eu estava no banheiro errado e dizendo que esta era o banheiro das mulheres. Eu respondi que sabia qual banheiro era e que eu estava no lugar certo, mas elas persistiram. Desde então eu evito banheiros públicos sempre que possível. Abebi, 34 anos. (BACHMANN; GOOCH, 2018, p. 10)

O relatório também demonstra que a transfobia possui impactos sobre o comportamento destas pessoas em público. $48 \%$ dos entrevistados não se sente confortável usando banheiros públicos, $40 \%$ relatou precisar ajustar a maneira de se vestir por eles temer sofrer discriminação ou assédio e que $44 \%$ evitar certas ruas completamente porque eles não se sentem seguros lá como uma pessoa LGBT. Conforme, se verifica nos depoimentos abaixo:

Somos constantemente questionados sobre a nossa existência, hostilizados e ridicularizado em nome de uma ideologia. Estamos constantemente expostos ao ódio e às críticas na mídia e na vida diária, como o público responder às atitudes da mídia. Estou farta de ser descrita como uma aberração mental. Esme, 32 anos (BACHMANN; GOOCh, 2018, p. 22)

$\mathrm{Na}$ minha vivência, enquanto homem transgênero, pude perceber os impactos da violência transfóbica em dois momentos diferentes da vida. Delimito o primeiro momento, como o período em que iniciei minha transição hormonal, quando a minha aparência expressava uma ambiguidade de gênero percebia vários olhares maldosos, xingamentos, ameaças e o segundo momento, este mais recente, quando a minha aparência ficou mais masculinizada, devido às mudanças corporais conseguidas através terapia hormonal, percebi que o meu caminhar pela cidade passou a ser mais confortável, os olhares maliciosos, as ofensas verbais e perseguições se tornaram bem menos frequentes.

Em relação à violência física, contabilizo três ataques. O primeiro deles, ocorrido no ano de 2014, quando o meu corpo não era lido completamente como um corpo masculino. Nesta ocasião, eu trabalhava em uma loja e próximo ao fechamento atendi um grupo de quatro homens. Desejei boa noite, me apresentei, como determinava a política de atendimento, expus os produtos e durante o atendimento, percebi que eles trocavam olhares debochados entre si, riam e faziam piadas a meu respeito. No fim do expediente, a caminho de casa fui surpreendido pelos mesmos homens, fui perseguido e agredido verbalmente até ouvir que "se eu queria ser homem, eles iriam me bater até eu virar um homem". A partir desta ameaça, fui tomado de sentimentos de terror e de extrema aflição diante da constatação de que nesse momento eu seria mais uma vítima, possivelmente fatal, de transfobia. Em meio a tanto sofrimento, percebi uma oportunidade de fuga e corri em direção à casa de um vizinho, que me socorreu e afugentou meus agressores.

O segundo ataque ocorreu cerca de duas semanas após o primeiro ataque, no mesmo local do primeiro ataque e mais ou menos no mesmo horário, o que me fez acreditar ser um ataque dos mesmos agressores. Eu caminhava pela rua com minha ex- companheira quando um carro avançou sobre nós e tentou nos 
atropelar. Inicialmente eu percebi o ataque como um acidente, minimizei o ocorrido pensando se tratar de um motorista bêbado. Só tomei (tomamos) consciência de que se tratava de uma violência após o motorista ter tentado nos acertar repetidas vezes, chegando a inclusive a subir a calçada, felizmente todas elas sem sucesso.

O terceiro ataque, e provavelmente não o último, ocorreu em um bar da cidade quando um homem desconhecido me agrediu gravemente após me confundir com um homossexual. Não me recordo completamente do fato, pois devido à gravidade dos ferimentos cheguei a perder a consciência. Segundo informações que tive de pessoas que presenciaram o fato o homem me agrediu e após eu cair desacordado, continuou a desferir chutes contra a minha cabeça e dizendo que iria me matar.

O que pude perceber com estes ataques é que a performatividade de gênero e a aparência física são fatores que podem causar um certo sentimento de segurança, quanto mais se aproximam ao padrão cis-hétero de normatividade, menor é a possibilidade de se sofrer um ataque ou seja, aparentar de alguma forma ser uma pessoa trans, seja pela forma do seu corpo, pela voz, pela ausência ou presença de pelos faciais ou qualquer outra característica considerada incoerente ao gênero que a pessoa se identifica. O que torna a experiência trans de viver na cidade um exercício cruel de vigilância, sobre o seu próprio corpo, de como ele se move e como ele se expressa. As consequências destes ataques forma repetidas crises de ansiedade, pânico e recolhimento social.

Outra percepção, diz respeito ao medo. Para uma pessoa trans caminhar pela cidade sem ser notado, agredido, assediado, ou ser alvo de gracejos ou ofensas é praticamente impossível. Sendo comum ouvir de outras pessoas que vivenciam a transgeneridade que: sair de casa é viver a incerteza de voltar pra casa vivo. Ora, se para Heiddeger (1986 apud DUARTE; NAVES, 2010) o sentido da existência do ser-no-mundo é viver a angústia de um ser-paramorte, ao se falar de pessoas trans podemos interpretar que esta angústia de ser-para-morte se torna muito mais latente, devido ao cenário de violência e vulnerabilidade em que vivem. O ser-pra-morte para este grupo, portanto, não representa simplesmente a consciência da finitude da vida mundana e sim um sentimento de medo constante, vindo de uma consciência de que suas existências podem ser mais breves do que é considerado como normal no ciclo natural da vida e que suas vidas estão condicionadas à vontade de outrem e que portanto, podem ser tomadas à força a qualquer momento.

\section{A Cidade dos Invisíveis: O Direito à Cidade e o Direito aos Corpos}

A maioria das cidades contemporâneas se constrói sobre o mito neoliberal da democracia social e urbana, ou seja, partindo do princípio de que a cidade é um espaço diversificado que pode ser usufruído e acessado por todos e que as pessoas viventes nestes espaços gozam (ou gozariam) do status de cidadãos. Entretanto sabe-se que para alguns segmentos sociais, dentre os quais destaco as pessoas trans, a experiência vivenciada pelas ruas da cidade mostra o grande distanciamento entre existir na cidade e possuir cidadania.

A lógica da cidade na pós modernidade não se constrói somente na 
produção do capital, mas na produção de desigualdades sociais e manutenção de estruturas de poder dividindo os cidadãos em categorias de sub-cidadãos; aqueles que pertencem a grupos sociais marginalizados, desprovidos de poder econômico-social e com baixo acesso à direitos; e de hipercidadãos; aqueles pertencentes às classes dominantes, com alto poder econômico-social e fácil acesso a direitos (RIBEIRO; SANTOS JUNIOR, 2003).

Ao aplicar estes conceitos propostos por Ribeiro e Santos Junior (2003) à realidade de pessoas trans é possível verificar que concomitantemente à situação econômica e social que lhes garante o status de cidadãos subalternos, outros estigmas sociais relacionados à atividade prostitucional, a prática sexual e a própria identidade de gênero as categoriza como abjeções. Segundo Goffman (2005) os estigmas são construídos através da criação de ideologias para explicar a inferioridade de um determinado grupo de sujeitos e dar conta do perigo que ela representa aos demais, racionalizando, algumas vezes, uma animosidade baseada em outras diferenças, tais como as de classe social.

Ao se tratar de pessoas trans além dos estigmas sociais que lhes foram historicamente imputados, estes sujeitos ainda vivenciam outra forma de subalternização a qual Butler (2000) chamou de abjeções. Segundo a autora, o abjeto refere-se às zonas 'inóspitas' e 'inabitáveis' da vida social. Os corpos abjetos são aqueles que não gozam do status de sujeito, status este que pode ser conseguido apenas ao habitar no signo do 'inabitável'. Estes estigmas e abjeções atribuídos a pessoas trans, interferem diretamente sobre sua sociabilidade,em sua cidadania e em no direito à cidade.

De acordo com o disposto na carta internacional de direto à cidade, todas as pessoas devem ter direito a uma cidade sem discriminação de gênero, raça, etnia e orientação sexual, política e religiosa. Sendo compreendida como cidade toda e qualquer grupamento organizado institucionalmente como uma unidade local de governo de caráter municipal ou metropolitano, urbano ou rural e,como cidadão todo habitante da cidade,seja a sua ocupação de forma permanente ou transitória. Sendo garantido a estes cidadãos a realização de todos os direitos humanos e liberdades fundamentais, tendo assegurados a sua dignidade e o bem estar coletivo.

Tendo em vista os princípios desta carta e os dados coletados sobre a violência transfóbica, podemos nos questionar se um corpo trans tem direito à cidade? Qual seria o lugar destes corpos na cidade? Quais seriam os direitos humanos daqueles que nem mesmo são considerados gente? A qual cidade efetivamente temos direito? Embora as perguntas aparentem ser meramente provocativas, nos convidam a fazer uma série de reflexões à respeito dos direitos humanos e da cidadania de pessoas trans.

Ao propor a existência da cidade dos invisíveis, me refiro a uma cidade metafórica, que a cidade hegemônica - cis-heteronormativa, instituída pela geografia e pela política - se recusa a enxergar. Se trata de uma abstração criada a partir de uma visão macro dos guetos, que coexiste simbioticamente neste ecossistema vivo e pulsante que é a cidade geográfica. Ela está inserida no tecido urbano da cidade, se utiliza de parte de sua estrutura urbana, porém se comporta como se ocupasse um plano independente no tempo, à medida que subverte a lógica de funcionamento da cidade, e no espaço, quando estabelece relações independentes de espacialidade, de territoriedade, de circulação e de 
comunicação.

A cidade dos invisíveis representa a teatralidade da vida noturna, é marcada por um cenário boêmio e extremamente erotizado,mas representa também a possibilidade que algumas pessoas trans tem de acessar minimamente as ruas da cidade, sem que sejam repelidos. Vale salientar que embora a comunidade tenha conhecimento sobre a existência das pessoas trans, um conjunto de práticas discriminatórias e marginalizantes, não permite que estas pessoas saiam da invisibilidade, forçando-os ao confinamento em guetos, quartos e ambiente privados, reduzindo seu acesso aos espaços públicos e, portanto, impedindo-lhes a ter direito à cidade (SILVA; SANTOS, 2015).

Carvalho e Macedo Jr (2017) afirmam que a sustentação de discursos heteronormativo colabora drasticamente com o apagamento, a exclusão e a discriminação de segmentos já opacos na sociedade, como é o caso da população trans.

Aliada à negação de direitos básicos, às interdições e à discriminação - vista principalmente na sacralização dos espaços públicos por meio do discurso de "lugar de respeito" - tem-se uma cidade interdita: uma cidade que nem todos podem acessar. (CARVALHO; MACEDO Jr, 2017, p. 114)

Macdowell (2010) ao analisar os espaços de sociabilidade de travestis, verificou que estas mulheres de certa forma possuem o direito à liberdade e o direito à cidade cerceados pela transfobia que sofrem nas ruas. $\mathrm{O}$ autor, afirma que a dinâmica em que estas pessoas estão inseridas lhes impõe que suas atividades diurnas se restrinjam ao ambiente privado de suas residências e que os espaços públicos sejam acessados somente durante a noite, ficando limitados aos contextos que giram em torno das atividades da prostituição. A respeito deste cerceamento e vigilância as quais estes corpos estão submetidos, Carvalho e Macedo Jr (2017) afirmam que:

Os mecanismos de controle dessa interdição são elementos sutis: através de micropoderes constituídos (como a religião e a família), interdita-se o sexo que contraria as normas sexuais tidas por legítimas, proíbe-se a sua expressão em público, reserva-se somente os espaços privados para o sexo possa falar de si, cria-se formas sutis de apagamento desses indivíduos marginais; afinal, se não se fala, não existe. (CARVALHO; MACEDO Jr, 2017, p114)

A rua representa o mundo, é o local onde se concentram as pessoas,o movimento, as dinâmicas sociais e suas interações, a rua também reflete os valores da sociedade e as regras morais que ordenam o espaço e os corpos que o habitam (CARVALHO; MACEDO Jr, 2017). Mas representa também um local de hostilidade e de violência, sobretudo quando se refere a pessoas trans. Turner, Whittle e Combs (2009) verificaram que 44\% das pessoas trans da união européia sofreram alguma forma de violência em público, sendo as mais comuns: comentários (44\%), agressão verbal (27\%), ameaças $(15 \%)$ e agressões físicas $(7 \%)$.

Considerando-se o contexto de violência ao qual pessoas trans estão 
expostas ao transitar pelas ruas, o silêncio, a escuridão e a (suposta) calmaria torna-se uma alternativa ao uso da cidade. Mas mesmo sob as cortinas da noite, o medo da violência ainda se faz presente no cotidiano e no imaginário destas pessoas, conforme relara Araruna (2017, p. 146-147):

Sobre estar na rua à noite sozinha. Vivenciei uma noite que me trouxe algumas reflexões sobre estupro e espancamento [...] Eu tive que andar ainda por algum tempo até chegar no lugar onde costumo estacionar meu carro, todos os dias, para ir trabalhar [...] fazer esse caminho de noite nunca pareceu tão pavoroso e demorado. Eu não encontrava ninguém, mas torcia que, caso encontrasse, não fosse um homem. Eu fiquei pensando na possibilidade desse encontro durante toda trajetória, e os resultados que imaginava eram sempre assustadores $[\ldots]$

Assim, eu não pude deixar de pensar na ameaça que um homem cisgênero é para mim, nessas situações. Sua representação dentro das relações de gênero faz com que ele possua o poderio de prescrever a mim diversos instrumentos de destruição: como o estupro, o espancamento e a própria morte.

Eu tive medo de ser alvo de estupro por um homem que soubesse que eu sou travesti; eu tive medo de ser alvo de estupro por um homem que achasse que eu era mulher cis e, ao descobrir que sou travesti, exercê-lo junto a outras violências por eu o ter "enganado"; eu tive medo desse homem me bater tanto até me matar porque eu frustrei sua tentativa de estupro por não ser a mulher que ele esperava. Enfim, eu colecionei alguns medos.

Sendo a rua um lugar de tensão, a vida da pessoa trans passa a se concentrar no ambiente doméstico. A casa, segundo Carvalho e Macedo Jr (2017), remete a um universo controlado, onde as coisas estão nos seus devidos lugares, sendo um lugar onde se subentende harmonia, calma, calor, afeto e sobretudo segurança.

Eu tive que sair da cidade, eu estava ficando assustado devido a pessoas violentas e intolerantes na área, incluindo os meus vizinhos próximos. Eu era atacado fisicamente na rua no meio do dia, os comentários feitos no supermercado quando eu estava cuidando da minhas coisas, destruíam as coisas do meu jardim. Eu temia pela minha própria segurança tanto que eu ficava confinado ao meu apartamento em muitas ocasiões por semanas ou mesmo meses (TURNER; WHITTLE; COMBS, 2009, p. 27)

Vale a pena ressaltar que nem sempre esses sentimentos são possíveis, devido às dinâmicas familiares centradas em valores cis-hetero normativos e ao contexto de violência doméstica ao qual muitos transgêneros estão submetidos. E, nessas condições a casa também pode ser um local relacionado a tensões e sofrimento. 
O direito à cidade é compreendido como o direito que todo cidadão possui de acessar e usufruir da cidade e de toda a estrutura que esta oferece. $\mathrm{O}$ direito à cidade se relaciona diretamente ao princípio da igualdade, uma vez que estes espaços são considerados públicos. Entretanto, compreendendo a cidade enquanto produto (e produtora) do capital podemos perceber a cidade como um espaço de contradições, conflitos e exclusões produzidas por relações de poder, dentre as quais destacamos para efeitos de recorte as relações de classe e de gênero.

Estando a população trans em situação de grave vulnerabilidade social e econômica, decorrente de complexos processos de exclusão e subalternização, o direito à cidade destas pessoas é bastante comprometido. Como assinala Araruna (2017, p. 138), "existir como um corpo dissidente das normas cisgêneras é o suficiente para que o nosso acesso às disposições que compõem o direito à cidade seja precarizado e correntemente violado."

Através dos dados coletados, das vivências de pessoas trans nas cidades e, estando eu incluso neste grupo, nas minhas próprias percepções foi possível concluir que a transfobia e a violência às quais este segmento social está exposto produz impactos diretos sobre o comportamento social e sobre a sua sociabilidade, dessa forma, sentimentos de angústia, medo, insegurança e até mesmo o desenvolvimento de fobias sociais fazem parte do cotidiano de muitas delas.

A cidade, que deveria ser o local de inclusão, de trocas e interações, se torna um local hostil e opressivo, controlado pela moralidade de uma sociedade capitalista dominada por valores cis-heteronormativos. O poder exercido na cidade e pela cidade (enquanto organização política) visa o controle e a regulação dos corpos e cria, mesmo que implicitamente, uma espécie de setorização moral dos espaços, onde se percebe que o uso da cidade é fortemente atrelado a rigorosos padrões de comportamento, de vestimenta e de gênero que vão definir quais zonas da cidade podem ser ocupadas e por quais corpos essas zonas pode ser ocupadas. Ou seja, a moralidade urbana institui quais são os 'lugares de respeito' e quais são os sujeitos que merecem ser respeitados.

\section{Referências}

ANTRA. Relatório 2017. Disponível em: <https://antrabrasil.org/relatorios/> Acesso em: maio de 2018.

ARARUNA, M. L. F. B. O DIREITO À CIDADE EM UMA PERSPECTIVA TRAVESTI: uma breve autoetnografia sobre socialização transfeminina em espaços urbanos. Periódicus - Revista de estudos indisciplinares em gêneros e sexualidades, v. 1, n. 8, p. 133-153, nov. 2017-abr. 2017.

ARGAN, G. C. A história da arte como história da cidade. São Paulo: Martins Fontes. 1998 
A Cidade dos Invisíveis: a Transfobia como um Instrumento de Segregação

Social e Urbana

BACHMANN, C. L.; GOOCH, B. LGBT In Britain: Trans Report. London: Stonewall, 2018.

BARCO, A. P. A constituição do espaço na fenomelonogia de Husserl. 2012. Dissertação (Mestrado em Filosofia) Faculdade de Filosofia, Universidade Federal de Goiás, Goiânia, 2012.

BARROS, J. D'. As Ciências Sociais e os modelos de cidade. Arquitetura Revista, v. 7, n. 1, p. 21-33, jan/jun. 2011

BATISTA, J. B. Abordagem fenomenológico-existencial do tempo a partir do livro XI de confissões, de santo Agostinho. Existência e Arte, v. 2, n. 2, p. 1-4, jan.-dez. 2006.

BUTLER, J. Corpos que pesam: sobre os limites discursivos do "sexo". In: LOURO, G. L. O corpo educado: pedagogias da sexualidade. $2^{\text {a }}$ Ed. Belo Horizonte: Autêntica, 2000.

CARVALHO, C. O.; MACEDO Jr, G. S. 'ISTO É UM LUGAR DE RESPEITO!': A construção heteronormativa da cidade-armário através da invisibilidade e violência no cotidiano urbano. Revista de Direito da Cidade, v. 9, n 1, p 103-116. 2017.

DUARTE, R.; NAVES, G. O ser-para-a-morte em Heidegger. Revista da Católica, Uberlândia, v. 2, n. 4, p. 64-82, Jul/Dez. 2010.

DURKHEIM, É. Da divisão do trabalho social. São Paulo: Martins Fontes, 1999.

ESTEVES. A. A criminalidade na cidade de Lisboa: uma geografia de insegurança. Lisboa: Colibri, 1999.

GOFFMAN, E. A representação do eu na vida quotidiana. 13. ed. Petrópolis: Vozes, 2005.

GUEDES, J. Cidade e espaço político. Psicologia USP, v. 14, n. 3, p. 73-78. 2003.

HEIDEGGER, M. Ser e Tempo II. Petrópolis: Vozes, 1989.

HERDT, G. Third sex, third gender: beyond sexual dimorphism in culture and history. New York: Zone Books, 1996.

HUSSERL, E. La crise des sciences européenes et la phénoménologie transcendentale. Traduit de l'allemand et préfacé par Gérard Granel. France: Éditions Gallimard, 2004.

ICASURIAGA, G. L.; RAMOS, M. H. R. Concepção de cidade na obra de 
A Cidade dos Invisíveis: a Transfobia como um Instrumento de Segregação

\section{Social e Urbana}

clássicos da teoria social. Temporalis, Brasília, v. 12, n. 24, p. 263-291, jul./dez. 2012.

JESUS, J. G. de. Orientações sobre identidade de gênero: conceitos e termos: guia técnico sobre pessoas transexuais, travestis e demais transgêneros, para formadores de opinião. Brasília: Autor, 2012.

Transfobia e Crimes de ódio: Assassinatos de pesssoas transgênero como genocídio. História Agora - (In)Visibilidade Trans 2, v. 16, n. 2, p. 101123. 2013.

LYNCH, K. A imagem da cidade. Rio de Janeiro: WMF - Martins Fontes, 2006.

LEFEBVRE, H. O Direito à cidade. $5^{\text {a }}$ edição. São Paulo: Editora Centauro, 2011.

MACDOWELL, P. de L. O espaço Degenerado: Ensaio sobre o lugar da travesti na cidade modernista. 2010. Dissertação (Mestrado em Antropologia Social) - Universidade de Brasília, Brasília.

PARK, R. E. A cidade: sugestões para a investigação do comportamento humano no meio urbano. In: VELHO, O. G. (org.). O Fenômeno Urbano. Rio de Janeiro: Zahar Editores, 1967. p. 13-28.

PASSAMANI, G. R. Homossexualidades e ditaduras militares: os casos de brasil e argentina. In: Fazendo Gênero 9: Diásporas, Diversidades, Deslocamentos, n. 9, 2010, Florianópolis. Anais... Florianópolis, 2010, p. 1-9.

PROJETO TRANS. Direitos e violência na experiência de travestis e transexuais na cidade de Belo Horizonte: Construção de um perfil social em diálogo com a população. Disponível em: $<$ http://www.nuhufmg.com.br/gde_ufmg/index.php/projeto-trans $>$ Acesso em: Maio de 2018.

REDE TRANS. Rede Nacional de Pessoas Trans - Brasil. Disponível em: $<$ www.redetransbrasil.org.br $>$ Acesso em: maio de 2018.

RIBEIRO, L. C. de Q.; SANTOS JUNIOR, O. A. dos. Democracia e segregação urbana: reflexões sobre a relação entre cidade e cidadania na sociedade brasileira. Revista eure, v. 29, n. 88, pp. 79-95, dic. 2003.

SCHWEICKARDT, J. C. Um olhar fenomenológico sobre a cidade. Somanlu, v. 1 n. 1 , p. 129-141, mai. 2000.

SILVA A. L. da; SANTOS, S. M. de M. dos. "O sol não nasce para todos": uma análise do direito à cidade para os segmentos LGBT. SER Social, Brasília, v. 17, n. 37, p. 498-516, jul.-dez. 2015 
A Cidade dos Invisíveis: a Transfobia como um Instrumento de Segregação

Social e Urbana

STONEWALL. What's in my area? Find LGBT services and community groups that are local to you. Disponível em: $<$ http://www.stonewall.org.uk/> Acesso em: Maio de 2018.

TRANSFEMINISMO. Trans* como termo guarda-chuva. Disponível em: $<$ https://transfeminismo.com/trans-umbrella-term/> Acesso em: Maio de 2018.

TRANSRESPECT. Comparative research data on 190 countries worldwide. Disponível em: <www.transrespect.org> Acesso em: Maio de 2018.

TURNER, L.; WHITtLE. S; COMBS, R. Transphobic Hate Crime in the European Union. London: BM Network, 2009.

VERAS, E. F.; GUASCH, O. A invenção do estigma travesti no Brasil (19701980). História, histórias. Brasília, v. 1, n. 5, p. 39-51. 2015.

VERGUEIRO, V. Trans* Sexualidade: Reflexões sobre a mercantilização do sexo desde uma perspectiva transgênera. Revista Periódicus. v. 1, maiooutubro, p. 1-17. 2014.

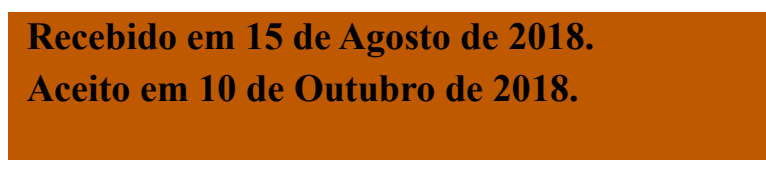

